\title{
A State-Wide Effort to Provide Access to Authentic Computer Science Education to Underrepresented Populations
}

\author{
Mohammed A. Qazi \\ Dept. of Mathematics \\ Tuskegee University \\ Tuskegee, AL USA \\ mqazi@tuskegee.edu
}

\author{
Jeff Gray \\ Dept. of Computer Science \\ University of Alabama \\ Tuscaloosa, AL USA \\ gray@cs.ua.edu
}

\author{
David M. Shannon \\ Dept. of Educational Foundations, \\ Leadership and Technology \\ Auburn University \\ Auburn, AL USA \\ shanndm@auburn.edu \\ Misty Thomas \\ Dept. of Curriculum and Teaching \\ Auburn University \\ Auburn, AL USA \\ mst0016@auburn.edu
}

\author{
Melody Russell \\ Dept. of Curriculum and Teaching \\ Auburn University \\ Auburn, AL USA \\ russeml@auburn.edu
}

\begin{abstract}
The Exploring Computer Science (ECS) curriculum provides foundational knowledge of Computer Science (CS) to high school students as a stand-alone course. ECS began in the Los Angeles Unified School District in the late 2000s where it gained eminence for broadening participation in computing (BPC), with Latinx students representing over $70 \%$ of enrollment. This experience report describes a partnership that consists of three Universities, dozens of school districts, the ECS team, and other stakeholders to bring the ECS curriculum in mainly rural school districts in Alabama that have a majority African-American student population. Sixty in-service teachers (one teacher per school) have received professional learning opportunities to gain knowledge and skills to teach ECS. Signs of early broader impacts are emerging: $78 \%$ of our ECS enrollment are underrepresented minority (URM) students with nearly half of the cohort consisting of female students. Students reported they were engaged in working collaboratively and sharing responsibilities with others. Furthermore, students who reported being more involved in the ECS course had deeper confidence in their ability to succeed in CS, reported greater overall outcomes, had more confidence in development of $21^{\text {st }}$ century skills, found the course more relevant, were more motivated to persist in CS, and exhibited increased interest in CS careers. We provide a comprehensive description of the partnership's accomplishments and the evaluation findings on student CS experiences and on teacher self-efficacy in ECS preparation and instruction. Our findings contribute to the BPC literature, specifically for schools with predominantly African-American enrollment in rural communities.
\end{abstract}

\footnotetext{
Permission to make digital or hard copies of all or part of this work for personal or classroom use is granted without fee provided that copies are not made or distributed for profit or commercial advantage and that copies bear this notice and the full citation on the first page. Copyrights for components of this work owned by others than ACM must be honored. Abstracting with credit is permitted. To copy otherwise, or republish, to post on servers or to redistribute to lists, requires prior specific permission and/or a fee. Request permissions from Permission@acm.org.

SIGCSE'20, March 11-14, 2020, Portland, OR, USA

(C) 2020 Association for Computing Machinery

ACM ISBN 978-1-4503-6793-6/20/03...\$15.00

https://doi.org/10.1145/3328778.3366955
}

\section{CCS CONCEPTS}

Social and professional topics $\rightarrow$ Professional topics $\rightarrow$ Computing education $\rightarrow \mathrm{K}-12$ education; Social and professional topics $\rightarrow$ Professional topics $\rightarrow$ Computing education $\rightarrow$ Computational thinking

\section{KEYWORDS}

Exploring Computer Science (ECS), Broadening Participation in Computing, Equity, Teacher Professional Development

ACM Reference format:

Mohammed A. Qazi, Jeff Gray, David M. Shannon, Melody Russell and Misty Thomas. 2020. A State-Wide Effort to Provide Access to Authentic Computer Science Education to Underrepresented Populations. In Proceedings of ACM Technical Symposium on Computer Science Education (SIGCSE'20). ACM, Portland, OR, USA, 6 pages. https://doi.org/10.1145/3328778.3366955

\section{Introduction}

The number of underrepresented minorities (URMs) in the computing workforce continues to be drastically inadequate. For example, African-American and Latinx students represent $30 \%$ of the US population, but constitute only $13 \%$ of the computing workforce [10]. The lack of URM participation limits creative input that results from diversity, which is a key aspect missing from the software products that are designed for use by our diverse society. A major contributing factor to the low representation of URMs in computing is the lack of uniform availability of rigorous Computer Science (CS) curricula at the K12 level [1] that builds and promotes computing pathways. In particular, families from African-American and Latinx communities tend to live in less-privileged areas where schools are under-resourced [2,7] and lack preparatory CS courses that are often available in more affluent school districts. This limits who has access to the most in-demand career options across the US states (e.g., software development [3]).

The ideal is for all students, regardless of socio-economic status, to have the opportunity to learn CS during their K-12 education. Even if CS is not a child's primary career choice, some knowledge of CS fundamentals is essential in our increasingly technological society. Computational thinking can serve as a 
foundational tool to assist in solving problems in other disciplines (e.g., a biologist who expresses a computation that invokes a machine learning library to infer knowledge about a genetics research problem being investigated). For this reason, CS should be prioritized in K-12 schools like any other core subject with attention to producing a large and diverse cadre of students with authentic CS experiences. It is with this ideal in mind that the ECS4Alabama partnership was formed consisting of Tuskegee University, the University of Alabama, Auburn University and other stakeholders with a special focus on introducing CS across Alabama in schools that have high populations of URMs.

\subsection{Broadening Participation with ECS}

For many years, AP CS A was the only nationally recognized high school level college preparatory course that taught authentic CS concepts. Unfortunately, AP CS A has not been popular among students from underrepresented communities. The Exploring Computer Science (ECS) curriculum was introduced in the late 2000s in the Los Angeles Unified School District (LAUSD) specifically to encourage more minorities and young women to gain CS experiences [5]. ECS is an introductory, but rigorous stand-alone course that provides CS preparation in the following six foundational units: 1) Human Computer Interaction; (2) Problem Solving; (3) Web Design; (4) Programming; (5) Computing and Data Analysis; and, (6) Robotics. The course is ideally suited for $9^{\text {th }}$ and $10^{\text {th }}$ graders as a gateway to AP CS A or the new AP CS Principles courses. ECS is known to be attractive to students, regardless of their background, because CS concepts are interwoven with practices that promote inquiry learning that is contextualized as culturally relevant [4]. As one of the ECS4Alabama teachers describes: "The lessons are easy to comprehend as well as interesting. They span several disciplines, and there is something in it for all students. This course truly encompasses equity and inquiry." In Alabama, the ECS course counts as a free elective or a career tech elective and will satisfy new legislation that requires a CS course to be offered at every high school in the state.

The ECS curriculum has emerged from the LAUSD collaboration as a viable curriculum for broadening participation in computing across the country. For example, McGee et al. [8] reported results that measured student expectancy-value and student learning from an ECS project for primarily urban students in Chicago and Wisconsin. Hu et al. [6] describe the first statewide deployment of ECS that served a large percentage of rural students, but the demographics in Utah were predominantly white. Our paper is an experience report that summarizes the ECS4Alabama partnership's efforts to introduce ECS into schools that have a dominant enrollment of traditionally underrepresented students (specifically, AfricanAmerican students who are from predominantly rural school districts) - an effort that has trained the largest number of rural African-American students on the ECS curriculum in the US.

\section{ECS4Alabama: A Statewide ECS Partnership}

The ECS4Alabama partnership was formed in 2016 to address the alarming lack of access to CS in Alabama schools. To make a measurable impact on diversity and broaden participation in CS education, the partnership's focus is to invite those schools in Alabama that have large underrepresented populations, primarily African-Americans from low-income, rural settings. Due to its resounding success as a curriculum that has broadened participation in CS in other regions of the US, ECS was identified as the curriculum to implement in Alabama school districts. The ECS4Alabama partnership includes various stakeholders that specialize in project implementation (e.g., three Universities, dozens of school districts, the ECS Program) and those that can contribute to sustaining the curriculum in the schools (e.g., the Alabama Department of Education). Furthermore, of the 60 high schools in the partnership (Figure 1), 51 schools serve a population that is in excess of $90 \%$ Free and Reduced Lunch.

\section{Figure 1: Schools in the ECS4Alabama Partnership}

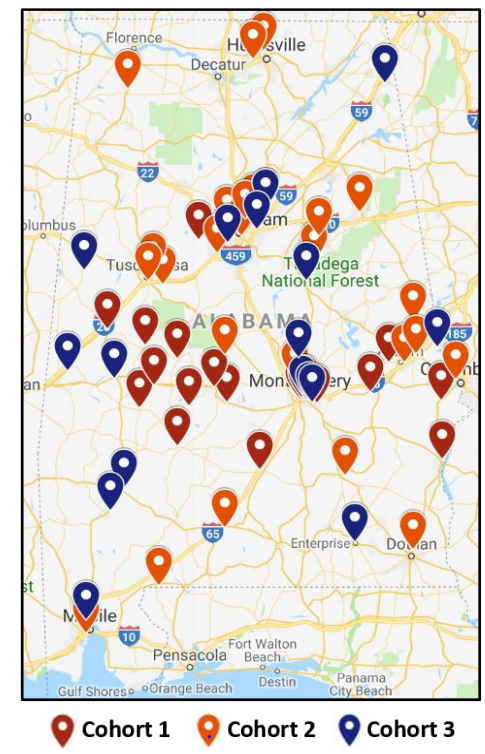

\subsection{Teacher Recruitment}

In Spring 2019, after a two-year effort, the ECS4Alabama partnership met its goal of recruiting 60 in-service teachers from high schools across Alabama for ECS preparation (each school provided one teacher to maximize the number of schools in the partnership). Teacher recruitment was implemented across three cohorts. As Table 1 shows, the three teacher cohorts are predominantly female and minority. This mix of gender, race and ethnicity was a teacher recruitment objective of the ECS4Alabama project.

Table 1. ECSAlabama Teacher and Student Diversity

\begin{tabular}{|c|c|c|c|c|c|c|}
\hline School Year & $\begin{array}{c}\text { \# Teachers } \\
\text { Trained on ECS }\end{array}$ & $\begin{array}{c}\text { \% Minority } \\
\text { (Teachers) }\end{array}$ & $\begin{array}{c}\text { \% Female } \\
\text { (Teachers) }\end{array}$ & $\begin{array}{c}\text { \# Students } \\
\text { Taking ECS }\end{array}$ & $\begin{array}{c}\text { \% Minority } \\
\text { (Students) }\end{array}$ & $\begin{array}{c}\text { \% Female } \\
\text { (Students) }\end{array}$ \\
\hline $2017-2018$ & 24 & $65 \%$ & $67 \%$ & 622 & $83 \%$ & $47 \%$ \\
\hline $2018-2019$ & 54 & $67 \%$ & $67 \%$ & 1804 & $81 \%$ & $44 \%$ \\
\hline $2019-2020$ & 60 & $68 \%$ & $\mathbf{6 9 \%}$ & $\begin{array}{c}1351 \\
\text { (Fall 2019) }\end{array}$ & $79 \%$ & $45 \%$ \\
\hline
\end{tabular}


Principals select teachers who are willing to learn a new subject with a passion to teach it, who then become core advocates for creating awareness about CS in their school. Teachers are either certified in Career Tech, Mathematics or Science, the majority of whom do not have any experiences in teaching CS. Student enrollment has been very strong with impressive enrollment by URMs. The enrollment numbers provided for 2019-2020 in Table 1 are for the 2019 Fall semester and will increase in Spring 2020 (some teachers who are on a semester schedule are not teaching ECS until Spring 2020 and those teaching in Fall 2019 may teach again in Spring 2020). Hence, the ECS enrollment at the end of the 2019-2020 school year will be much larger than indicated.

\subsection{ECS4Alabama Teacher Professional Development}

The focus of the ECS Professional Development (PD) model is to foster specific instructional practices based on inquiry learning and culturally relevant pedagogy among participating teachers. During all PD meetings, teachers are placed in collaborative groups to forge teams and community building as they receive the preparation to teach the 6 units of the ECS course. Teachers wearing their "student hats" form clusters and engage in ECS lessons. ECS facilitators serve as observers and provide feedback as needed. The inquiry-based processes that teachers gain through the PD sessions reflect the learning that they are expected to promote among students in their ECS classrooms.

The ECS PD model is organized in several phases. Teachers receive preparation to teach Units 1 and 2 of ECS during a five day Summer Institute. Those teachers then commence teaching these two units in the Fall. Quarterly meetings are held during the school year to train teachers on the last 4 units. Teachers return for another five day Institute over the following summer to allow them to revisit the inquiry and equity-based framework of ECS and the first two ECS units that are the critical scaffolding [4] to the problem-solving focus of the ECS course.

\subsection{Virtual PD Communities}

The first Summer Institute in the year-long ECS PD cycle serves as a critical step to initiate important community-building opportunities among the teachers, an outcome of this model that they highly value. Because ECS4Alabama trains one teacher per school, teachers do not have access to the traditional in-school support through peers. To address this void, ECS4Alabama Teacher Leaders engage the ECS teacher community in peermentoring through online discussion boards (Google Groups) where teachers post questions about ECS, provide answers, make comments and share useful information. As such, virtual professional learning communities (PLCs) are created and maintained for continuous support and to counter any feelings of isolation by teachers as they implement the ECS curriculum in their classrooms. This assistance has been especially helpful to novice teachers who are teaching CS for the first time.

\subsection{ECS4Alabama Teacher Leaders}

Teacher leadership development is an important part of the ECS4Alabama partnership. To serve in this important capacity, teachers must have completed the ECS training, demonstrated key leadership qualities such (e.g., willingness to go beyond the basic expectations of the partnership) and be a strong advocate for the ECS program. Two teachers are serving in the role of Teacher Leader and are providing support to their peers. They manage the PLCs by helping curate and generate discussion on the project's Google Groups, answer technical questions from community members, provide supplemental resources for instructors to teach ECS and assist in recruiting and advertising for the project.

\subsection{Building Capacity to Provide ECS Leadership and Training from within the ECS4Alabama Community}

The long-term outlook for CS education in Alabama looks very promising. A recent state law mandates that every high school in Alabama must offer CS courses by the 2020-21 school year, and every middle school by 2021-2022. Because of the awareness that ECS4Alabama has been able to establish at the Alabama Department of Education regarding the positive impact of ECS on youth in Alabama schools, the course will be a prime candidate for implementation at each of the state's 470 high schools. As new ECS teachers are trained across the state, they will need sustained mentoring in various aspects of ECS implementation. This support for novice teachers will be provided by the robust ECS Teacher Leader network being established by the ECS4Alabama partnership. In addition, the PD that has been initially offered through the project uses out-ofstate trainers, which in the long-term is unsustainable. To improve the cost-effectiveness of future ECS trainings, ECS4Alabama is preparing teachers from its own ECS teacher community to serve as ECS trainers that can facilitate PD in Alabama and even at other states in the US. To-date, one ECS teacher has become a certified trainer and three additional ECS teachers from Alabama are gaining readiness.

In the important context of inclusion and diversity in CS, the ECS4Alabama Teacher Leaders and emerging trainers are all African-American women. As such, they are serving as role models to other teachers (the majority of whom are teachers of color) as an inspiration to contribute to nation's BPC effort. Moreover, the project's success with the recruitment of African American teachers for ECS teaching provides more opportunities for students to see people of color in CS education.

\section{ECS Impact in Alabama}

In the Fall of 2017, 24 Cohort 1 teachers stepped into their classrooms to teach ECS for the very first time in Alabama. These teachers taught to an inaugural cohort of approximately 622 students, $83 \%$ of whom were URMs (Table 1). In addition, nearly half of the students consisted of young women. With the addition of 30 Cohort 2 teachers in 2018-2019, over 1,800 students took ECS across the state, maintaining nearly the same diversity measures. 
These diversity trends continue this new school year with early 2019-2020 data revealing that of the over 1,300 students who are enrolled in ECS classes, nearly $80 \%$ are URMs and $45 \%$ young women. These measures point to a ground-breaking project for the state of Alabama in the context of BPC. Although the partnership is benefiting from the large underrepresented demographics of the region, it is the first time that a concerted effort is in place to bring challenging CS curriculum to some of the most underprivileged regions of the US.

Over the past two academic years, teachers and students have experienced several positive outcomes as they have participated in the ECS curriculum, as described in the following subsections.

\subsection{ECS4Alabama Teachers}

Teachers reported positive outcomes resulting from their ECS $\mathrm{PD}$, as well as increased confidence and implementation of the ECS curriculum, resulting in positive student outcomes.

3.1.1 Teacher PD. During the fall of each academic year, teachers were asked to respond to questions related to the impact of the summer PD and the extent to which they applied what they learned from the Summer Institutes. In Fall 2017, 23 of the 24 Cohort 1 (C1) teachers provided feedback on their Summer 2017 PD experience while 27 of the 35 Cohort 2 (C2) teachers did so in Fall 2018 about their Summer 2018 PD experience. Both cohorts were asked to rate the quality of the summer PD materials and components. Overall, feedback was very positive with all 9 items averaging 4.0 or above, using a 5point scale. Teachers especially believed that the PD was aligned to the ECS curriculum ( $M=4.74$ for $\mathrm{C} 1$ and $M=4.59$ for $\mathrm{C} 2)$ and rated the quality of the workshop materials $(M=4.65$ for $\mathrm{C} 1$ and $M=4.63$ for $C 2)$ and model lessons $(M=4.52$ for $C 1$ and $M=4.44$ for $\mathrm{C} 2)$ at a very high quality.

3.1.2 Teacher Implementation. When teaching ECS in their first semester after the Summer Institute, cohort participants reported that they most frequently reviewed summer workshop materials $(\mathrm{M}=4.48$ for $\mathrm{C} 1$ and $\mathrm{M}=4.62$ for $\mathrm{C} 2)$ as well as communicated regularly with each other $(M=3.61$ for $\mathrm{C} 1$ and $\mathrm{M}=4.40$ for $\mathrm{C} 2$ ). The majority of each cohort relied on these materials as their sole or primary source $(76.1 \%$ for $\mathrm{C} 1$ and $86.7 \%$ for C2). A matched sample of Cohort 1 teachers was also used to determine which changes occurred over their first year of teaching CS. After one year of teaching, these teachers reported an increase in CS efficacy, integration of ECS units in class and implementation of specific ECS student objectives. The increases for $\mathrm{C} 1$ were statistically significant with large effect sizes $(\mathrm{t}=2.83$, $\mathrm{p}<.01, \mathrm{~d}=.943$ for integration ECS units and $\mathrm{t}=2.59, \mathrm{p}<.01, \mathrm{~d}=.866$ for implementation of ECS objectives).

\subsection{ECS4Alabama Students}

A total of 398 students completed surveys in Spring 2018 and 393 in Spring 2019. The typical student identified as Black or African American (61.1\% in 2018, 62.7\% in 2019), Hispanic or Latino (16.7\% in 2018 and $22.2 \%$ in 2019) and without a disclosed disability ( $83 \%$ in 2018 and $89 \%$ in 2019). Gender was not requested in 2018, but $55.9 \%$ identified as male in 2019 .
3.2.1 Student Survey Scales. Twelve (12) scales related to the implementation and outcomes associated with the ECS curriculum were used. These scales were based on the work of the Barriers and Supports to Implementing Computer Science (BASICS) study [9]. All scales used a 5-point response scale and reliability estimates were very supportive, ranging from .744 to .944 in 2018 and from .752 to .957 in 2019.

3.2.2 Student Participation. In general, average responses were higher in 2019 when compared to the previous year cohort. Students from both years indicated a high level of small group activity and work that required them to take intellectual risks (trying new things and creating something original). They also indicated that teachers facilitated student involvement on challenging work and interest in CS. These findings are summarized in Table 2.

Table 2. ECS Student Outcomes

\begin{tabular}{|l|l|l|l|l|}
\hline & & $\begin{array}{c}\text { Spring } \\
\mathbf{2 0 1 8}\end{array}$ & & $\begin{array}{c}\text { Spring } \\
\mathbf{2 0 1 9}\end{array}$ \\
\hline Scale & $\mathbf{N}$ & Mean (SD) & N & Mean (SD) \\
\hline ECS Scales & & & & \\
\hline $\begin{array}{l}\text { Student Participation } \\
\text { - Small Groups }\end{array}$ & 372 & $4.07(.92)$ & 344 & $4.20(.85)$ \\
\hline $\begin{array}{l}\text { Student Participation } \\
\text { - Discussion }\end{array}$ & 372 & $3.73(.98)$ & 344 & $3.84(.94)$ \\
\hline $\begin{array}{l}\text { Student Participation } \\
\text { - Cognitively } \\
\text { Demanding Work }\end{array}$ & 372 & $3.73(.88)$ & 344 & $3.89(.85)$ \\
\hline $\begin{array}{l}\text { Student Participation } \\
\text { - Autonomy }\end{array}$ & 371 & $3.75(.91)$ & 342 & $3.80(.91)$ \\
\hline $\begin{array}{l}\text { Student Participation } \\
\text { - Intellectual Risks }\end{array}$ & 370 & $3.89(.88)$ & 343 & $3.95(.85)$ \\
\hline $\begin{array}{l}\text { Teacher Facilitation of } \\
\text { Cognitively } \\
\text { Demanding Work }\end{array}$ & 371 & $3.95(.92)$ & 346 & $4.07(.84)$ \\
\hline $\begin{array}{l}\text { Teacher Facilitation of } \\
\text { Student Autonomy }\end{array}$ & 370 & $3.76(.98)$ & 346 & $3.83(.94)$ \\
\hline $\begin{array}{l}\text { Teacher facilitation of } \\
\text { Student Interest }\end{array}$ & 370 & $3.96(.91)$ & 346 & $4.01(.89)$ \\
\hline Outcomes & 344 & $3.54(.89)$ & 321 & $3.72(.91)$ \\
\hline $\begin{array}{l}\text { ECS Units - } \\
\text { Usefulness }\end{array}$ & $37.57(.93)$ & 320 & $3.69(.88)$ \\
\hline $\begin{array}{l}\text { ECS Units - } \\
\text { Confidence }\end{array}$ & $3.82(.88)$ & 345 & $3.87(.83)$ \\
\hline ECS Outcomes & $4.18(.77)$ & 326 & $4.14(.83)$ \\
\hline $\begin{array}{l}\text { Outcomes - 21 st } \\
\text { Century Skills }\end{array}$ & 340 & & & \\
\hline a-5-point response scale & & & & \\
\hline
\end{tabular}

3.2.3 ECS Outcomes and 21st Century Skills. Overall, students reported very positive outcomes associated with the ECS course $(\mathrm{M}=3.82$ in $2017-18$ and $\mathrm{M}=3.87$ in 2018-19) and even more positive outcomes related to their $21^{\text {st }}$ Century skills $(M=4.18$ in 2017-18 and $M=4.14$ in 2018-19). Using a retrospective pre/post survey to indicate the extent to which they experienced 
improvements $(1=$ not at all, $5=\mathrm{a}$ great extent $)$ since participating in the ECS course, each item related to the overall ECS outcomes and $21^{\text {st }}$ Century skills measurement scales was examined. These responses are summarized in Table 3. Overall, student responses indicated great improvement, with average responses exceeding 3.5 for 9 of the 10 ECS outcome items in 2018 and 10 of 10 in 2019. The greatest improvements were reported for creativity ( $M=4.07$ in $2017-18$ and $M=4.10$ in 2018-19), problem solving ( $M=3.99$ in $2017-19$ and $M=3.97$ in 2018-19), critical thinking $(M=3.96$ in $2017-18$ and $M=3.95$ in 2018-19), and working effectively with other students $(M=3.94$ in 2017-18 and $M=4.05$ in 2018-19). In addition to overall reported outcomes related to ECS, students were also asked to respond to 10 items related to confidence in their $21^{\text {st }}$ Century skills. Students were very confident in these skills as responses averaged above 4.0 for all items each academic year.

Table 3. ECS Outcomes and $21^{\text {st }}$ Century Skills

\begin{tabular}{|l|l|l|l|l|l|l|}
\hline $\begin{array}{l}\text { ECS Student } \\
\text { Reported } \\
\text { Improvement }\end{array}$ & \multicolumn{5}{|c|}{ Spring 2018 } & \multicolumn{3}{c|}{ Spring 2019 } \\
\hline ECS Outcomes & N & Mean & SD & N & Mean & SD \\
\hline $\begin{array}{l}\text { Your ability to be } \\
\text { creative and think } \\
\text { of new ideas }\end{array}$ & 368 & 4.07 & 1.02 & 340 & 4.10 & .940 \\
\hline $\begin{array}{l}\text { Your ability to use } \\
\text { problem solving } \\
\text { skills }\end{array}$ & 362 & 3.99 & 1.04 & 345 & 3.97 & 1.00 \\
\hline $\begin{array}{l}\text { Your critical } \\
\text { thinking skills }\end{array}$ & 368 & 3.96 & 1.03 & 344 & 3.95 & .923 \\
\hline $\begin{array}{l}\text { Your ability to } \\
\text { work effectively } \\
\text { with others }\end{array}$ & 370 & 3.94 & 1.12 & 344 & 4.05 & 1.02 \\
\hline $\begin{array}{l}\text { Your knowledge of } \\
\text { CS }\end{array}$ & 368 & 3.84 & 1.06 & 345 & 3.89 & 1.02 \\
\hline $\begin{array}{l}\text { Your awareness of } \\
\text { careers in CS }\end{array}$ & 369 & 3.83 & 1.15 & 344 & 3.80 & 1.14 \\
\hline $\begin{array}{l}\text { Your computer } \\
\text { science skills }\end{array}$ & 367 & 3.82 & 1.09 & 341 & 3.88 & 1.02 \\
\hline Your interest in CS & 369 & 3.69 & 1.33 & 345 & 3.80 & 1.18 \\
\hline $\begin{array}{l}\text { Your desire to take } \\
\text { another CS class }\end{array}$ & 369 & 3.63 & 1.32 & 345 & 3.71 & 1.27 \\
\hline $\begin{array}{l}\text { Your desire to } \\
\text { pursue a career in } \\
\text { CS. }\end{array}$ & 370 & 3.47 & 1.42 & 342 & 3.57 & 1.33 \\
\hline Scale (1=not at all, 5=a great extent) & & & & 0 \\
\hline
\end{tabular}

3.2.4 Relationship of ECS Components to Reported Outcomes. Using findings from the ECS scales, relationships were examined between student participation and teacher facilitation with other ECS scales related to usefulness, confidence, outcomes, $21^{\text {st }}$ Century skills, motivation, efficacy and career interests. All correlations were statistically significant $(\mathrm{p}<.001)$.

3.2.5 Student Participation and ECS Outcomes. Relationships between student participation and reported outcomes revealed moderate to large size effect with correlations ranging from .239 to .593 . Overall, students who reported being more involved in the class found the class more useful, had more confidence, reported greater overall outcomes, had more confidence in their $21^{\text {st }}$ Century skills, found the ECS course more relevant, were more motivated to persist in CS, had more confidence in their ability to succeed in CS and were more interested in CS careers. This was especially true in relation to student engagement in cognitively demanding work and autonomy scales. That is, students who reported having autonomy and involvement in developing solutions to solve real problems in class reported very positive outcomes associated with the ECS class.

3.2.6 Teacher Facilitation. Correlations between teacher facilitation and student reported outcomes were also moderate to large, ranging from .278 to .593. As with the student participation scales, teacher facilitation of students engaging in cognitively demanding work, autonomy and interest were statistically associated with student perceptions of usefulness, confidence, outcomes, $21^{\text {st }}$ Century skills, motivation, efficacy and career interests. That is, when students reported teachers facilitating their autonomy, interest and engagement in work to develop solutions to solve real problems, they reported more positive outcomes associated with the ECS class.

\section{Lessons Learned}

Project leaders have gained several insights into the challenges of introducing and sustaining a curriculum like ECS in Alabama schools. We discuss these here as "lessons learned".

\subsection{Recruitment: Engaging in Conversations with School Officials is Key}

The ECS4Alabama partnership had to overcome numerous teacher recruitment challenges that are factors often impacting under-resourced schools (e.g., staffing issues, overburdened school administrators). For this reason, recruitment materials that were shared electronically with Principals and Counselors were often overlooked or ignored. Placing the project on the "radar of school officials" necessitated in-person visits to schools by project leads who traveled thousands of miles across Alabama over two years for recruitment efforts. Ultimately, this exhausting approach turned out to be most efficacious for teacher recruitment as school officials took the time in person to hear about ECS, asking questions and learning how the course has the possibility of "opening doors" to students who may otherwise not have an opportunity to engage in a CS curriculum and learn a critically important subject. Personal visits also reassured school officials that ECS4Alabama is a legitimate Professional Development program designed in the best interests of the students.

\subsection{Importance of School Administrators}

The project's experiences with the initial difficulties in attracting the attention of school administrators to learn about the ECS4Alabama project reveals a deeper systemic issue with the operating procedures in Alabama's schools, especially those that are drastically under-resourced such as those in the ECS4Alabama partnership. It is critical for the sake of students' 
academic growth that practices and routines by K-12 leadership change allowing them to find the time to explore important educational opportunities that are shared with them, especially those that are offered at no cost to the schools. Each project may not have the persistence of the ECS4Alabama leaders to pursue traditional recruitment approaches like one-on-one meetings.

\subsection{Sustaining ECS in ECS4Alabama Schools}

The 60 teachers trained by the ECS4Alabama project are pioneers and trend-setters for the state in educating students in ECS. An ECS4Alabama survey administered to project teachers reveals that $88 \%$ would like to teach ECS long into the future with another $79 \%$ willing to receive training on other CS courses. These are remarkable findings as all project teachers are teaching CS out of field. These facts are a testimony that with the appropriate training, educators in any area can learn to teach ECS and develop a passion for it. As such, our ECS teachers will serve as role models who will continue to advocate for CS in their schools and inspire thousands of students to take ECS and other CS courses.

The reality is that the $\mathrm{K}-12$ teaching profession is prone to teacher turnovers. Teachers earn promotions, move to a new school or eventually retire. Thus far, seven teachers trained by the ECS4Alabama program have been affected by turnovers. Retraining is thus needed, costing the program valuable resources. School Principals also change frequently in Alabama schools, which has been equally problematic for the project. Having no awareness of ECS, they sometimes do not realize how critical it is for ECS to be taught by a trained teacher. Due to complex internal dynamics of the schools, we have witnessed situations where new Principals assign ECS to teachers who have not received any formal training in ECS, while the teacher who had gone through training is re-assigned. In such cases, not only do the training and resources go to waste, the effectiveness of the course is significantly reduced in many ways, which can be detrimental to our collective mission of preparing large and diverse cadre of students with CS experiences.

There are many recent positive events that will help us to sustain the ECS4Alabama project, beyond the duration of our National Science Foundation funding. The new legislation mandating that all schools in Alabama must offer a CS course will be a catalyst to help ECS maintain longevity in schools and that it be taught by a trained ECS teacher. Additionally, discussions by project leaders with Alabama's Department of Education about the aforementioned challenges has led to the identification of an official at the Department of Education who will serve as a liaison for the project and help to address the challenges of ECS teacher continuity in ECS schools. Related to funding, Alabama legislators have allocated over one million dollars in the state's Education Trust Fund, which is expected to increase in future years. The solution to the ubiquitous problem of teacher turnover, however, has remained elusive. This is not unique to the ECS4Alabama initiative.

\section{Conclusion}

There are a range of indicators, both qualitative and quantitative, that suggest a strong positive impact of the project in terms of the preparation of new teachers for CS instruction and the learning of CS by students. Notable broader impacts as a direct result of the implementation of the ECS4Alabama effort include: 1) the creation of a very supportive network of teachers across 60 high schools, with the majority from high-needs settings, assist each other to address challenges and share accomplishments; and, 2) an opportunity for students from these schools, many of whom come from socio-economically underprivileged backgrounds, to access CS, an enriching STEM subject that is typically offered in more affluent districts. These students are gaining authentic experiences in critically important CS topics that are missing from the traditional high school curriculum, such as problem solving, coding, web designing, robotics and computational thinking. In the process, they are learning critically important $21^{\text {st }}$ Century skills, gaining awareness of careers in computing and the prospects for a better quality of life that accompanies these careers due to their high earning potential. Even if CS is not an area of deep interest for students, immersion in computational concepts and critical thinking opportunities will be beneficial to them regardless of their areas of passion.

\section{ACKNOWLEDGMENTS}

This project was sponsored by NSF award \# 1639971. We also wish to acknowledge the contributions to the ECS4Alabama project by the ECS Professional Development team consisting of Gail Chapman, Tangela Crocker, Jessica Jarboe, LaTanya McSwine, Tanga Myers, Dale Reed and Floresa Vaughn.

\section{REFERENCES}

[1] Code.org (2019). Make Your Own Advocacy Materials, https://code.org/promote/morestats

[2] Firebaugh, G., \& Acciai, F. (2016). For blacks in America, the gap in neighborhood poverty has declined faster than segregation. Proceedings of the National Academy of Sciences of the United States of America, 113(47), 13372-13377.

[3] Fottrell, Q. Here's the No. 1 highest paid, most in-demand job in every American state, MarketWatch, August 28, 2019, https://www.marketwatch.com/story/heresthe-no-1-highest-paid-and-fastest-growing-job-in-every-us-state-2019-08-20

[4] Goode, J., Margolis, J., Chapman G. (2014). Curriculum is not enough: The educational theory and research foundation of the Exploring Computer Science professional development model. In Proceedings of the 45th ACM Technical Symposium on Computer Science Education, 493-498.

[5] Goode, J., Margolis, J. (2011). Exploring Computer Science: A Case of School Reform Transactions on Computing Education 11 (2): 12:1-12:16 (2011).

[6] Hu, H. H., Heiner, C., McCarthy, J. (2016). Deploying Exploring Computer Science Statewide, SIGCSE 2016, pp. 72-77.

[7] Lee, T., "Low-Income Black and Latino Students Hit Hardest in Public Schools", https://www.newsweek.com/low-income-black-and-latino-students-hit-hardestpublic-schools-778897

[8] McGee, S., McGee-Tekula, R., Duck, J., McGee, C., Dettori, L., Greenberg, R., I., Snow, E., Rutstein, D., Reed, D., Wilkerson, B., Yanek, D., Rasmussen, A. M., Brylow, D. (2018. Equal Outcomes 4 All: A Study of Student Learning in ECS, SIGCSE 2018, pp. 50-55.

[9] Outlier Research and Evaluation (2016). BASICS-Barriers and Supports to Implementing Computer Science. Instruments to measure CS Implementation Retrieved from http://outlier.uchicago.edu/basics/

[10] U.S. Equal Employment Opportunity Commission, Diversity in High Tech https://www.eeoc.gov/eeoc/statistics/reports/hightech/ 